Publisher homepage: www.universepg.com, ISSN: 2707-4668 (Online) \& 2707-465X (Print)

https://doi.org/10.34104/ajssls.020.01930199

Asian Journal of Social Sciences and Legal Studies Journal homepage: www.universepg.com/journal/ajssls

\title{
Do the Differences in Ideas about Social Action Influence Sociological Analysis? A Review Article
}

\author{
Ashim Kumar Nandi* \\ Department of Sociology, University of Barishal, Barishal-8254, Bangladesh.

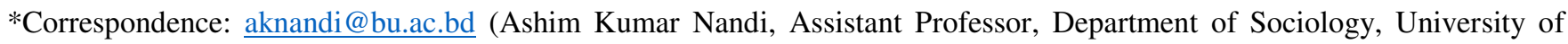 \\ Barishal, Barishal-8254, Bangladesh).
}

\begin{abstract}
This article reviews different thoughts of modern sociologists about social action to examine how the differences in meaning of social action influence sociological analysis. This article also discusses the implication of these differences in meaning of social action to sociological analysis. Four articles and two books of selected modern sociologists have been reviewed to explore the research questions of this article. This article finds that modern sociologists take social action as an important concept in sociological analysis. Classical sociologists, such as Max Weber, also suggest taking social action as a central focus in sociological study. This article observes that whether action is exerted based on structure or the actor's self-interpreting power is one of the key issues in the ideas of modern sociologists.
\end{abstract}

Keywords: Social action, Sociological analysis, Research questions, Framework, and Modern sociological theory.

\section{INTRODUCTION:}

Various theorists provide different thoughts about social action; although in some points they agreed (Goffman, 1956; Giddens, 1984; Coleman, 1994). Analysis of social action has a significant effect on sociological research (Schrag, 1959). But there is a lack of research on the evaluation of the action frame-work in this regard. The search results in Scopus, Google Scholar, and Web of Science did not show any evidence of recent research on the effect of distinct views of social action on sociological research (Bonna, 2021). Difficulty of the evaluation of action framework has some reasons such as "flexibility of the framework" for steady development, adjustment, and reconstruction of the ideas of social action (Schrag, 1959). Moreover, theory of action went through a significant review which is experienced by- (1) the use of action theory to distinct actual social situations UniversePG I www.universepg.com
(Parsons, 1954); (2) examination of the influence of social changes (Parsons et al., 1956) and so on.

In addition, analysis of the action framework has difficulty in evaluation for the lack of certainty in the interpretation of terms and for the lack of hypothesis/ propositions (Schrag, 1959). Inconsequence of the above-noted points, this article presents distinct views of modern sociologists about social action to explore how the differences change the analysis in sociological study. The implication of these differences in thoughts to sociological analysis is also discussed in this article. Thus, the article answers two questions: firstly, what are the ideas of Erving Goffman, Herbert Blumer/ George Herbert Mead, James S. Coleman, and Anthony Giddens regarding social action, and secondly, what are the implications of the differences in the ideas of these thinkers in sociological analysis? 


\section{Thoughts on Social Action Erving Goffman}

From a dramaturgical perspective (Goffman, 1956) explained how an individual acts. He stated that individuals influence others during social interaction. Taking a functional/pragmatic view he explained an individual act based on his 'initial information' and try to make his "first impression" to others as good and planned as possible and expects desired behaviors from others for his 'moral right' to be valued that individual of his kind have a right to expect (Goffman, 1956). By 'encounter', he meant an interaction "which occurs throughout any one occasion when a given set of individuals are in one another's continuous presence" (Goffman, 1956). This special situation or encounter is important in Goffman's work since he explained his important concepts (role distance) in this special setting. His idea of social action is thus explained by imagining the setting. In addition, social action follows a structure, and an individual's preestablished view about others and his own. Either his the article show of an individual's performance in 1956's book or his explanation of role distance referring to the merry-go-round or surgical setting in 1961's article, he explained how individuals act based on his knowledge of the social setting he encounters. For Goffman, performers always try to make an impresssion to adapt with the pre-established socially expected roles as a social actor, thus a performer "accentuates certain matters and conceals others" during his performance which he executes through mystification (Goffman, 1956). Social actors-/performers maintain the relevant definition of the situation as a team which Goffman mentioned is not linked to social structure rather an encounter. From the point of view of front stage and backstage, individuals can understand with their social mobility that the behaviors they are used to with their previous role are almost similar in their new roles which is a kind of dramaturgical trouble individual experiences when he acts. Sometimes an individual does not respond to an immediate situation, which Goffman referred to as "communication out of character", the reason for this performance is team members' response "stands back from" the imagined response (Goffman, 1956). Moreover, loyalty, discipline, and circumspection, in the dramaturgical sense, are essential for sustained social action. Role distance UniversePG I www.universepg.com refers to actions which effectively convey some disdainful detachment of the performer from a role he is performing. Goffman argued that role distance falls between role obligations and actual role performance (Goffman, 1961). That is, role distance means a kind of action that shows an actor's contemptuous disengagement from the role he/she is supposed to perform. Taking example of performance of a surgical operation, Goffman defines situated activity systems as "a face-to-face interaction with others for the performance of a single joint activity, asome-what closed, self-compensating, self-terminating circuit of interdependent actions" (Goffman, 1961). By this concept he examined the complexities of concrete conduct. Proving an example of a merry-go-round, he argued at five years of age the situation has changed in the merry-go-round. This changing situation deserves change in his actions. Now the image that is created for him is an image from which he withdraws by actively manipulating the situation. This changed behavior separates his role from him. This separateness is called role distance. In this sense, role distance refers to that behavior that suggests that the actor perhaps has some extent of disaffection from and resistance against the role. The meaning of role distance changes for different ranked individuals (Goffman, 1961) said, "Charm and colorful little informalities are thus usually the prerogatives of those in higher office..." However, role distance creates division of labor or role differentiation. In addition, an actor has a simultaneous multiplicity of selves. Thus, while an actor participates in an activity system he participates in other matters, in relationships, in multi-situated systems of activity.

\section{Herbert Blumer/George Herbert Mead}

Blumer comments and debates on Mead's concepts on social action. He saw human beings as an actor who has a self. Self is a process, not a structure. For this self, an actor can judge and interpret the things as a mechanism of self-interaction that guides his action. To act people must set a goal, plan how to behave, explain the actions of others, and understand the situation. Moreover, Blumer said that symbolic interaction is a formative process. Like symbolic interaction, actors explain each other's body language and act based on meaning generated by the explanation in the situation. Blumer used joint action instead of Mead's 
'social act'. Social act refers to the "larger collective of action that is constituted by the fitting together of the lines of behavior of the separate participants" (Blumer, 1966). Family dinner is an example of joint action. Important characteristics of joint action are, firstly, the core of society belongs to the continuing trial of action. Thus, action is the basis of all structures of relations. Secondly, individuals can see and treat action. Thirdly, each joint action must have a background and so on (Blumer, 1966). Similarly, Mead observed human society as a "diversified social process in which people were engaged in forming joint actions to deal with situations confronting them" (Blumer, 1966).

\section{James S. Coleman}

Actors do not have full control of their own activities since these activities are under the control of other actors. Structure is a system of action where actors act purposefully to expand the awareness of their interests. This awareness creates interdependence among actors (Coleman, 1994). An actor might compensate for the right to control his own actions in two conditions, firstly, if he already holds that right, secondly, if "he holds the right to dispose of the right" (Coleman, 1994).

Coleman, (1994) thinks that corporate actors use formal rules to make choices. These formal rules are called systems which help moving "micro level of individual action to the macro level of social choice. For example, casting vote" (Coleman, 1994). Coleman (1994) argued that conceptual foundations of the development of the mathematical structure are: "actors and events as the two basic elements of a system of action, linked together by the control of actors over resources and events and the interest of actors in resources and out-comes of events". Coleman, (1986) discussed that there are two theoretical problems: "how the actions of the actors combine to exert system-level behavior and how those purposive actions are in turn shaped by constraints that result from the behavior of the system". We might be cautious to take his one idea that argues that any type of authority ultimately depends on a conscious choice from the standpoint of the person. Moreover, how could we compute that shows the cost benefit of perceived alternative action? We might also be cautious to accept the given influence of the transition from traditional to deliberately generated structures. Lastly, we could say he did not provide enough evidence of an empirical nature of his ideas.

\section{Anthony Giddens}

Giddens, (1984) argued that human action is demonstrated as a duree, which is an endless progress of conduct. Everyday action is featured as a reflexive monitoring of activity, which incorporates the action of both person and the others. He said actors always follow the context in which they move, they monitor the flow of their activities with activities of others. This activity of monitoring is a continuous process. The actor also endlessly monitors social and physical aspects, which facilitate actors to ensure that others are following them. He depicted his ideas of action using a figurative description where he showed that un-intended consequences of action cause 'unacknowledged conditions of action' Giddens, (1984). 'Unintended consequences of action' influenced by the reflexive monitoring of action which in turn influenced 'rationalization of action' Giddens, (1984). Motivation of action affects rationalization of action. Here, Giddens, (1984) refer to rationalization of action as an end-less theoretical realization of the background of their activity that is maintained by actors. He argued that rationalization of action and reflexive monitoring are different from its motivation. Giddens, (1984) uses his idea of duree to explain one of the key conceptsagencies. He gave an example of his speaking English which is his intentional act but through this act he is reproducing the English language which is not intentional. Unintentional acts cause the unintended consequences of reproducing the English language. In this regard he critically refers the concept of Durkheimsuicide. He elaborated that suicide is uncommon among most of the human acts in terms of intentions. Giddens, (1984) also provides an example of an officer on a submarine to illustrate the ideas of intentions. By this example (Giddens, 1984) show that submarine officer's action, i.e., pulling the lever, was intentional but the consequence of the action, i.e., pulling the wrong lever which caused sank of the Bismarck, was unintentional. Actor is imagined as a perpetrator, since "whatever happened would not happen if that individual has not intervened" (Giddens, 1984). Giddens, (1984) summarized the discussion of intentionality and unintentionality with the discussion of agent's power. 
He stated that the consequence of action did not happen if an actor did not act, although the action was out of that actor's control. In discussing forms of institution, Giddens explains the dimensions of the duality of structures which is also important to under-stand social action. Interpretative schemes are included within an actor's stock of knowledge. This knowledge is enforced spontaneously to assist communication. Actors use stock of knowledge to produce and reproduce interaction. The stock of knowledge is also used to describe or to give reason.

\section{Differences in Ideas}

1) Structure: Coleman explains structure as a system of action that the actors are purposive and each actor having the goal of maximizing the realization of his interests that gives the interdependence to their actions. On the other hand, Giddens argued that structure is internal to the individual. He (1984) added that structure is recurrently involved which includes "situated activities of human agents, reproduced across time and space". For Goffman, action follows an existing structure.

2) Profane part of Goffman's ideas see social action is exacted by society which is opposite of Blumer/Mead's view. In contrast, the sacred part of Goffman's ideas of social action describes an individual who is able to be touched by humor, he/she can show his types and so this part is like the view of Blumer/Mead. However, Blumer/ Mead see social action as an ongoing process of action (i.e., constructing structure).

3) Influence in action: Coleman thinks an individual's action is affected by others' action. But according to Blumer/Mead, 'a mechanism of self-interaction' helps an individual in guiding his/her conduct. However, Goffman thinks that skills of maneuvering are essential for role distance, in other words, the skills of maneuvering help individuals to act, to execute role distance.

4) Principle/process of action: Coleman thinks the actor's principle of action is to maximize their realization of interests. According to Blumer/ Mead, actors judge and interpret the actions of others then plan a prospective way of behavior and then act. However, for Goffman, defensive activity is the reason of an individual's decline to embrace role self.

5) Methodological approach: Blumer/Mead' methodological approach is opposite of objective approach. Goffman's approach might be an objecttive approach.

6) Categories of action: Blumer/Mead describes two types of social action: conformity and deviance. On the other hand, Giddens sees action has two forms, intentional and unintentional. However, Coleman finds differences in action between natural actors and corporate actors.

7) Goffman sees self as looking glass, whereas Mead/Blumer sees it as an object.

8) According to Goffman we can see the social situation from outside, but Mead/Blumer suggests understanding everything from the point of view of the actor.

9) Goffman discussed a situated activity system, whereas Mead/Blumer discussed joint action.

10) Coleman argued that rationality and egoism affects behavior. But according to Blumer/Mead, in symbolic interaction, individuals interpret the action of others and respond according to that interpretation.

\section{Similarities in Ideas}

a) By 'interpretative schemes', Giddens shows an individual can describe and give reason. To do it, obviously, an individual depends on his/her stock of knowledge. At least partially, this idea is like Blumer/Mead since they also think that individuals interpret the behavior of others and then respond. But we might be cautious to apply the idea of Giddens in relation to the existing stock of knowledge of an individual, since it is not clear what he exactly meant by stock of knowledge: does this knowledge follow only structure which he meant interior to the individual or it is like an ongoing process? If the stock of knowledge only follows the structure, then it is like the ideas of Goffman.

b) Goffman argues that an individual can have simultaneous multiplicity of selves. This idea is similar to the idea of Blumer/Mead. Because Blumer/Mead argued that an individual interprets the action of others before responding, we 
might assume that that individual will also be conscious about his/-her simultaneous multiplicity of selves when he/she interprets others' actions.

c) Giddens sees power in actors which is important for action. We might say Goffman also thinks actors have power, power of maneuvering, power of declining to embrace role self.

d) Both Goffman and Blumer/Mead believe that an individual acts understanding his situation.

e) Coleman, (1994) assumed that "individuals are rational, and they are egoistic". To some extent, this point is like the ideas of Blumer/Mead if we think ego as self.

\section{Implication of Different Views on Social Action in Sociological Analysis}

\section{Erving Goffman}

Role distance might be effective for research focused on well-being and worthwhile lifestyle. It might be helpful to bring a positive attitude in life through role distance from negative activity. Goffman argued that role distance falls between role obligations and actual role performance (Goffman, 1961). This gap might cause trouble for sociologists. This can turn their own direction of analysis. For example, in an in-depth interview, respondent provides a deep account that covers many aspects of a question, and if the researcher is not skilled there is a possibility of role distance through a deviance of interpretation of the data. Sometimes researchers try to understand respondents' descriptions with the researcher's own standpoint that also can divert the direction of analysis. (Goffman, 1961) himself suggests that the "concept of role distance provides a sociological means of dealing with one type of divergence between obligation and actual performance". He adds the more extensive the trappings of a role, the more opportunity to display role distance (Goffman, 1961). This argument could be a basis for studying the contribution of different professionals including sociologists in their own field. Goffman took the 'surgery' as a case to test his role distance concept. We can examine similar social settings in different places with cultural varieties to compare how different people behave. Goffman, (1961) argued that "certain maneuvers which act to integrate the system require for their execution individuals who do not fully embrace their situated selves". For maneuvering one needs skills, so we might investigate whether those who are more skilled in strategy setting are more able to role distance? His dramaturgical perspective might be applied in the investigation of social establishment as restricted systems. The establishment could be viewed technically, politically, structurally, and culturally. Moreover, the individual personality, social interaction, and society can be taken inter-disciplinary attempts as one framework (Goffman, 1956). His ideas can be applied to the same areas of social life in different cultural settings such as in Asia, Latin America and so on.

\section{Herbert Blumer/George Herbert Mead}

Blumer/Mead's ideas are important to analyze deep reasons for various social problems, which might be difficult using quantitative approaches. Because they suggest analyzing social action from an actor's view. It is more like a micro sociological approach that can focus on micro level problems. However, it might be a challenge to capture all micro level phenomena and cover all potential actors in analyzing social problems. Structure has been imagined as a standard to understand social action, as Blumer/Mead said that "social action falls into two general categories: conformity, marked by adherence to the structure, and deviance, marked by departure from it. Because of the central and determinative position into which it is elevated, structure develops as an object of sociological study and analysis" (Blumer, 1966). Blumer (1966) himself acknowledged that the methodology he discussed is opposite of the objective approach, since he suggests taking the "role of the actor and seeing the world from his standpoint". But it might be challenging for the researcher to separate his/her own ideology and subjective views apart from the views of actors whom he/she has taken as a respondent. An important aspect of Blumer/Mead's ideas is that they see actors who are constructing the structure and society as a "vast number of occurring joint actions" (Blumer, 1966). This aspect gives us a new way of analyzing structured actors' views and understanding society.

\section{James S. Coleman}

Coleman's theoretical view of social action focuses highly on rationality. But there are many situations where we do not have 'options' so in that case ratio- 
nality becomes irrelevant. For example: we can take a recent example of a coronavirus outbreak. Globally many countries closed their borders despite the huge risk of economic and other crises. Because to stop or delay the coronavirus outbreak, affected countries have no other options that can rationally be thought of. We can think of another example. If a university decides to shift all classes and examinations online in response to the outbreak and does not ask students about their opinions (practically this is not a time to ask students because there is no option of yes/no or agree/disagree). Students are bound to participate in the online courses, although their programs are not online programs. Even if a student prefers doing class at university campus, he/she has no options right now. This example might be a very silly example, but what we can understand from this example is that there are some situations when we do not have options of thinking rationally.

Moreover, there is a concern regarding testability. How could we test Coleman's, (1994) assumptions such as "whether the cause of altruistic behavior is egoism?" We find many researchable interests in his book, but he did not show how these could be transformed into specific empirical questions. In addition, he did not show any concern with conceptual problems. Even he did not show how we could operationalize his terms. Coleman, (1986) expressed his concern about new change in post watershed research which is "largely statistical and largely confined to explaining individual behavior" on the basis of "causal explanation based on statistical evidence that replaced purposive explanation" (Demiessie et al., 2021). Moreover, he recommended that we require a proper theoretical model that shows a relationship between individual actions and systematic functioning to conduct an analysis of systematic actions (Coleman, 1986).

\section{Anthony Giddens}

Giddens' idea might be referred to as abstract, so it is a challenge to use it empirically. He compared different theories of social action before presenting his own idea. An important aspect of his ideas is that he argued motivation is the potential for action. He said that motive gives the plan. This idea could be interesting to social psychologists in their analysis. Moreover, he argued that the actor/individual is a perpetrator since "whatever happened would not happen if that indiUniversePG I www.universepg.com vidual had not intervened. Action is a continuous process like a flow in which the reflexive monitoring which the individual maintains is fundamental to the control of the body that actors ordinarily sustain throughout their day-to-day lives" (Giddens, 1984). Giddens' structuration theory might be helpful in analyzing how leadership does work in an organization. For example, if we take rules and resources of an organization as structure and individuals as agents of an organization, then we can assume that interaction between structure and agency, in other words, interaction between rules and regulations with individuals can develop better leadership in an organization.

\section{CONCLUSION:}

The ideas of modern sociologists explained many unanswered questions of social action. These ideas might be used to analyze different new social and global phenomena, for example, how we behave during unexpected crises such as a coronavirus outbreak which reduces our options and affects the global community at the same. Their views also contribute to the questions of the role of structure and self-interacting power of actors in executing action. It helps to think about how cultural and social background can affect an individual's action.

\section{ACKNOWLEDGEMENT:}

This article is written based on an examination paper of the "Modern Sociological Theory" course in the Department of Sociology at Stockholm University, Sweden. This publication has been produced during my scholarship period at Stockholm University, which is funded by the Swedish Institute (SI reference number: 13910/2019).

\section{CONFLICTS OF INTEREST:}

Author discloses no potential conflict of interest.

\section{REFERENCES:}

1) Blumer, H. (1966). Sociological implications of the thought of George Herbert Mead. The American Journal of Sociology,71(5), 535-544. http://www.jstor.org/stable/2774496

2) Bonna S. (2021). The bad effects caused by policy prescription and financial assistance by IMF on developing countries, Asian J. Soc. Sci. Leg. Stud., 3(5), 172-177. https://doi.org/10.34104/ajssls.021.01720177 
3) Coleman JS. (1986). Social theory, social research, and a theory of action. The American Journal of Sociology, 91(6): 1309-1335.

http://links.jstor.org/sici?sici=0002-9602\%28198 605\%2991\%3A6\%3C1309\%3ASTSRAA\%3E2.0. CO\%3B2-6

4) Coleman JS. (1994). Foundations of Social Theory,pp. 1-993. The Belknap Press of Harvard University Press, Cambridge. USA.

https://hdl.handle.net/2027/heb.31522

5) Demiessie MG, Hossain MR, and Shirin S. (2021). The gateway to well-being and happiness: re-defining individualism, voluntary simplicity and civilization, Asian J. Soc. Sci. Leg. Stud., 3(3), 59-74.

https://doi.org/10.34104/ajssls.021.059074

6) Giddens A. (1984). Elements of the theory of structuration, pp. 1-40. in Giddens, A. (ed.), the Constitution of Society: Outline of the Theory of Structuration, University of California Press, Berkeley.

https://www.wiley.com/en-us/The+Constitution+of + Society\%3A+Outline+of+the+Theory+of+Struct uration-p-9780745665283

7) Goffman E. (1956). The Presentation of Self in Everyday Life, pp. 1-162. Social Sciences Res- earch Centre, University of Edinburgh, Edinberg.

https://monoskop.org/images/1/19/Goffman_Ervin g The Presentation of Self in Everyday Life.pd $\underline{\mathrm{f}}$

8) Goffman E. (1961). Role distance, pp. 84-152. In Goffman E. (ed.), Encounters: Two Studies in the Sociology of Interaction, The Bobbs-Merill Company, Inc., New York.

https://www.worldcat.org/title/encounters-two-studies-in-the-sociology-of-interaction/oclc/710786

9) Schrag C. (1959). Comments on the general theory of action. Alpha Kappa Deltan, 29(1): 4652.

10) Parsons T. (1954). Essays in Sociological Theory. The Free Press, Glencoe, Illinois. https://www.worldcat.org/title/essays-in-sociolog ical-theory/oclc/253489

11) Parsons et al. (1956). Family, Socialization, and Interaction Process. The Free Press, Glencoe, Illinois.

https://www.worldcat.org/title/family-socializatio n-and-interaction-process/oclc/259911

Citation: Nandi AK. (2021). Do the differences in ideas about social action influence sociological analysis? a review article, Asian J. Soc. Sci. Leg. Stud., 3(5), 193-199. https://doi.org/10.34104/ajssls.021.01930199 @) 